\title{
A trilha musical de Moacir Santos para Os Fuzis no contexto das produções do Cinema Novo e a predominância do silêncio narrativo ${ }^{1}$
}

\section{Moacir Santos's film score for Os Fuzis in the Cinema Novo context and thepredominance of the narrative silence}

iD) Lucas Zangirolami Bonetti
lucas@lucasbonetti.com.br

Resumo: O presente artigo estuda a trilha musical de Moacir Santos para o filme Os Fuzis por meio da análise musical e historiográfica. Para se alcançar esse objetivo, foram primeiramente contextualizadas as principais tendências da produção de trilhas musicais nos anos 1960 no Brasil, de modo a traçar possíveis paralelos de entendimento. O tema principal do filme, que é efetivamente a única composição de Santos presente na trilha musical, foi transcrito em partitura e devidamente analisado. Além disso, também foram abordadas outras inserções musicais que não foram compostas por Santos, mas que passaram por seu crivo de diretor musical da produção. Por fim, foi de grande interesse para a pesquisa perceber o uso narrativo e estrutural do silêncio dentro da trilha sonora, dialogando com outros aspectos estéticos do filme, e se aproximando de outras produções do período.

Palavras-chave: Moacir Santos. Trilha musical. Os Fuzis. Silêncio narrativo.

\footnotetext{
1 Esse trabalho é um resultado parcial de três projetos de pesquisa financiados pela Fundação de Amparo à Pesquisa do Estado de São Paulo (FAPESP), que abordam as trilhas musicais de Moacir Santos: Processos n ${ }^{\circ}$ 2012/11195-4, 2013/23992-9 e 2015/03111-3. Essas bolsas resultaram na dissertação de mestrado (BONETTI, 2014) e tese de doutorado (BONETTI, 2018) do autor.
} 
Abstract: In the present paper, I study Moacir Santos's film score for the movie Os Fuzis through musical and historiographical analysis. To achieve this goal, I contextualized the main trends of film music productions in Brazil in the 1960s, in order to draw possible parallels of understanding. The main theme, which is the only Santos's composition present in the film score, was transcribed in musical notation and properly analyzed. Besides that, cues that were not Santos's compositions were thoroughly addressed, as they were organized by him as the Musical Director of the production. Finally, I could notice the great importance of the narrative and structural use of silence, interacting both to further aesthetic aspects of the movie and other productions of the period.

Keywords: Moacir Santos. Film scores. Os Fuzis. Narrative silence. 
A trilha musical de Moacir Santos para Os Fuzis no contexto das produções...

Lucas Zangirolami Bonetti

\title{
As trilhas musicais no cinema brasileiro dos anos $1960^{2}$
}

\begin{abstract}
A década de 1960 foi marcada por uma grande efervescência cultural, com muitos movimentos artísticos iniciando suas atividades concomitantemente. No plano musical estavam confluindo na música popular a bossa-nova, o samba jazz, o tropicalismo, a jovem guarda e correntes de música instrumental; e na música erudita, o movimento Música Nova; já no cinema, surgiram o Cinema Novo e o Cinema Marginal. Em se tratando especialmente dos movimentos voltados à linguagem cinematográfica, "[...] foram desenvolvidas diversas iniciativas de regulamentação das atividades do cinema, algumas governamentais e outras de profissionais diretamente relacionados ao campo artístico" (FINK; CALHADO, 2008, p. 1), sendo a criação da Embrafilme ${ }^{3}$ uma das iniciativas mais representativas dessa época. Além da Embrafilme, também podemos citar outras iniciativas, como a Difilm ${ }^{4}$ e o Instituto Nacional de Cinema ${ }^{5}$. Dessa maneira, pode-se perceber que houve um favorecimento a toda essa agitação, que veio tanto dos artistas quanto da movimentação social do período.
\end{abstract}

Também é notável a postura estética da época, que desembocou no Cinema Novo. Com relação a essa afirmação, Fink e Calhado (2008, p. 1) comentam que o cinema brasileiro

[...] refletiu isso adotando uma postura de engajamento político e uma estética inovadora que, por seu caráter transformador, acompanhava o desejo da revolução política. Influenciados pelo neorrealismo e pela nouvelle vague, os cineastas brasileiros optaram por produzir filmes de baixo orçamento, com a utilização de câmeras leves e sem o apoio de tripés, seguindo o postulado da "câmera na mão e uma ideia na cabeça".

\footnotetext{
20 primeiro subcapítulo do presente artigo é uma adaptação derivada de uma publicação anterior: BONETTI, 2012.

3 A Embrafilme foi criada por meio de um decreto-lei no ano de 1969 e tinha como objetivo financiar a produção, em todas as suas etapas, do cinema brasileiro. A empresa foi extinta no ano de 1990.

4 A Difilm nasceu em 1965 da sociedade de cinco empresas, das quais os principais diretores do Cinema Novo eram proprietários (FINK; CALHADO, 2008).

5 O Instituto Nacional de Cinema (implantado em 1966), ou INC era um “órgão que incorporou o Instituto Nacional de Cinema Educativo e cujos objetivos eram fiscalizar e normatizar assuntos referentes ao cinema nacional" (FINK; CALHADO, 2008).
} 
A trilha musical de Moacir Santos para Os Fuzis no contexto das produções... Lucas Zangirolami Bonetti

Ainda sobre aspectos sociais, Jean-Claude Bernardet ressalta que "[...] o cinema brasileiro percorreu todo o caminho necessário para que enfim não possamos mais deixar de nos examinarmos a nós próprios, de nos interrogarmos [...] sobre nossa responsabilidade social e política" (2007, p. 65). Contudo, ainda segundo o próprio Bernardet, toda essa canalização de energias para fazer do cinema uma "ferramenta revolucionária" não foi alcançada da maneira esperada:

Os filmes não conseguiram travar diálogo com o público almejado, isto é, com os grupos sociais cujos problemas se focalizavam na tela. Se os filmes não conseguiram esse diálogo é porque não apresentavam realmente o povo e seus problemas, mas antes encarnações da situação social [...], e também porque os filmes se dirigiam, de fato, aos dirigentes do país (BERNARDET, 2007, p. 65).

Nos anos 1960, contemporâneo ao movimento do Cinema Novo, também se desenvolvia o chamado Cinema Marginal, que trabalhou sobre influências de neoimpressionistas e modernistas, especialmente influenciados pela obra de Oswald de Andrade e músicos tropicalistas. A articulação fílmica também se deu de maneira divergente ao Cinema Novo, com maior fragmentação narrativa.

Toda tradição cinematográfica tem seu próprio contexto. Todo filme é parte de um contexto maior que ele mesmo; todo filme é um discurso respondendo a outros discursos; todo filme responde e ecoa aqueles que o precederam. Para apreciar os filmes brasileiros recentes, é importante conhecer a tradição da qual vieram. Desde que o cinema brasileiro tornou-se internacionalmente famoso por meio do Cinema Novo, é especialmente importante saber que muito veio antes do Cinema Novo e muito veio desde o Cinema Novo. JOHNSON; STAM, 1995, p. 19, tradução nossa) ${ }^{6}$.

$\overline{6 \text { Every cinematic tra }}$ dition has its own intertext. Every film is part of a text larger than itself; each film is a discourse respon- 
A trilha musical de Moacir Santos para Os Fuzis no contexto das produções... Lucas Zangirolami Bonetti

O Cinema Novo é reconhecido como a maior expressão cinematográfica brasileira dos anos 1960 e tornou-se referência para muitas produções posteriores, desde sua linguagem até sua ideologia. Os principais nomes ligados ao movimento são Glauber Rocha, Carlos Diegues, Joaquim Pedro de Andrade, Nelson Pereira dos Santos e Ruy Guerra. Esse grupo de diretores e roteiristas marcou o período com suas impressões estéticas, tanto pelas temáticas abordadas quanto pelas produções em si (fotografia, movimentação de câmera etc.). Glauber Rocha proferiu a famosa frase "uma ideia na cabeça e uma câmera na mão", que retrata bem o espírito desbravador dessa fase. A afirmação dialoga especialmente com a falta de recursos técnicos que muitas vezes se enfrentava, mas que era confrontada pelo discurso dos diretores.

Um fato importante de se lembrar é que "na história do cinema tem sido absolutamente comum que uma nova geração que começa a se estruturar, para se legitimar e se tornar hegemônica, rompa com o grupo anterior" (MARTINELLI, 2002, p. 159). Isso aconteceu em diversos movimentos na Europa e no Brasil e com o Cinema Novo não foi diferente, ele se sobrepôs às produções das companhias Vera Cruz e Atlântida de maneira fulminante, rompendo com paradigmas estabelecidos e assumindo uma nova postura perante o espectador.

Um dos próprios participantes do movimento, Carlos Diegues, considera difícil definir o que foi o Cinema Novo, "isso prova a profundidade do movimento, a sua complexidade criadora, a ausência de condições imobilizantes, academicizantes" (DIEGUES, 1999, p. 52). Percebe-se que o grupo caminhou no intuito de fazer um cinema sem amarras, como eles almejavam. No excerto abaixo, Diegues (1999, p. 27) comenta, com um sentimento misturado de orgulho e rancor, o que foi para ele o Cinema Novo:

\footnotetext{
ding to other discourses; each film answers and echoes those that have preceded it. To appreciate current Brazilian films, it is important to know the tradition from which they spring. Since Brazilian cinema became internationally famous though Cinema Novo, it is especially important to know that much came before Cinema Novo and that much has come since Cinema Novo (JOHNSON; STAM, 1995, p. 19).
} 
A trilha musical de Moacir Santos para Os Fuzis no contexto das produções...

[...] Isso seria mais uma razão pra acabar com essa conversa fiada de Cinema Novo. Não tem mais sentido ficar falando de uma turma da esquina, quando não existe mais esquina nenhuma. O Cinema Novo é um rótulo vazio que serviu para destacar uma geração (da qual muito me orgulho de ter feito parte) que fundou o cinema moderno (técnica de produção e linguagem) no Brasil.

Outros cineastas produziram concomitantemente com o Cinema Novo, contudo sem integrarem o movimento. Pessoas como Luiz Sérgio Person, Roberto Santos e Walter Hugo Khori têm em seus currículos alguns longas-metragens datados da década de 1960 que apontam para um direcionamento particular. Na segunda metade dessa década também é possível encontrar um novo grupo de cineastas enquadrado no rótulo do já comentado Cinema Marginal. Dentre os diretores que fizeram parte desse movimento estão Rogério Sganzerla, Júlio Bressane, Ozualdo Candeias, dentre outros, tendo os dois primeiros fundado a produtora Balair, que existiu por poucos anos. O Cinema Marginal

[...] produziu filmes baratos numa sucessão notavelmente rápida, rejeitando um cinema bem feito em favor de uma "tela suja" e de uma "estética do lixo". [...] Os filmes traziam marcas da opressão econômica, inscrevendo neles próprios - pelo som rangente e inaudível e imagens granuladas - a própria precariedade da produção (STAM apud GUERRINI, 2009, p. 29)

Com essa afirmação, de certa forma, podemos ver pontos de encontro entre o Cinema Marginal e apenas a primeira fase do Cinema Novo, pois nos "filmes da última fase do Cinema Novo, já se percebe maior preocupação com recursos financeiros e com o retorno da bilheteria, [...] agora visto como conservador" (GUERRINI, 2009, p. 29). 
A trilha musical de Moacir Santos para Os Fuzis no contexto das produções...

Pode-se iniciar a discussão sobre a música dos filmes nos anos 1960 a partir dos parâmetros propostos por Irineu Guerrini Jr. em seu livro A música no cinema brasileiro: Os inovadores anos sessenta (2009). O autor aponta para o fato de que, como já é sabido, o cinema dessa década sofreu sérios problemas orçamentários e isso se refletiu diretamente na música desses filmes. Muitas vezes o padrão sinfônico/orquestral foi deixado de lado para se realizar produções com poucos músicos. Em certos casos, apenas um músico interpretou a trilha musical de todo o filme, ou parte dele. Por exemplo, Sérgio Ricardo em Deus e o Diabo na Terra do Sol, de Glauber Rocha. De certa forma, esse problema de verba delineou todo um parâmetro estético, sendo que, posteriormente, em produções que teriam orçamento suficiente, seus diretores preferiram adotar o padrão estabelecido. Ainda citando Guerrini, também é notável o intenso uso de gravações já existentes nas trilhas musicais dos filmes, "como a música erudita e sinfônica dos grandes mestres - especialmente Villa-Lobos - jazz e canções populares" (2009, p. 32). Esse uso também tende a reafirmar a falta de verba para a contratação de compositores que façam uma trilha musical original para o filme. No que se refere aos estilos de trilha musical, Guerrini categoriza a década de 1960 em quatro pontos referenciais:

- Música erudita brasileira, com inclinação estética voltada para a música contemporânea europeia da primeira metade do século XX. Entre os principais compositores envolvidos estão Ester Scliar, Marlos Nobre, Damiano Cozzela, Júlio Medaglia, Guilherme Magalhães Vaz e especialmente o compositor Rogério Duprat. Nota-se grande presença de nomes ligados ao movimento Música Nova, sendo que alguns deles ainda flertam com a música popular.

- Bossa Nova, MPB e Tropicalismo: todos esses gêneros trilharam seus percursos, ou parte deles, na década de 1960. Logo, a concomitância temporal atuou como facilitadora para a confluência dessas duas linguagens. 
A trilha musical de Moacir Santos para Os Fuzis no contexto das produções... Lucas Zangirolami Bonetti

- Música dita folclórica: "Já havia o uso de temas folclóricos na produção anterior, [...] mas este se aproveita de uma evolução tecnológica - gravadores portáteis e de boa qualidade - para gravar música in loco e acentuar o caráter realista, documental" (2009, p. 35).

- Villa-Lobos. A música desse compositor foi amplamente empregada como trilha musical de diversos filmes da época, os exemplos mais famosos são os de Deus e o Diabo na Terra do Sol e Terra em Transe, de Glauber Rocha; Menino de Engenho, de Walter Lima Jr.; Os Herdeiros e A Grande Cidade, de Carlos Diegues; e Macunaíma, de Joaquim Pedro de Andrade.

Alguns dos principais compositores para cinema que atuaram na década de 1960 foram Sérgio Ricardo, Rogério Duprat, Guilherme Vaz, Remo Usai e Moacir Santos. Como já comentamos anteriormente, é possível perceber na música de cinema dessa época que os compositores e responsáveis pelas trilhas musicais também apresentam características comuns, tendo, inclusive, apesar das formações díspares, experiências profissionais semelhantes.

O processo composicional de Moacir Santos para o audiovisual, especialmente na escolha das formações instrumentais, de certa forma difere da estética mais "magra" do período cinemanovista. Essa estética "magra" refere-se à "estética da fome", apresentada por Glauber Rocha em seu manifesto de 1965. "A 'fome' não é apenas apresentada nas telas [...], nem sofrida, como preço de sua coerência política, por alguns de seus realizadores [...], mas está também no modo de concepção e produção dos filmes" (GUERRINI, 2009, p. 29). Essa concepção está presente em todos os âmbitos das produções, inclusive no plano sonoro, que utilizou poucos instrumentistas e muitas gravações já existentes, diferentemente do cinema brasileiro da década anterior, que ostentava grandes orquestras em suas trilhas musicais.

Ou seja, apesar das limitações encontradas nas produções do período, as trilhas musicais de Santos ainda apresentam características orquestrais tais quais as encontradas nas décadas 
A trilha musical de Moacir Santos para Os Fuzis no contexto das produções... Lucas Zangirolami Bonetti

anteriores. Sendo assim, podemos encarar seu trabalho de trilhas musicais como uma transição entre o padrão precedente e a estética consolidada nos anos 1960. Apesar disso, Os Fuzis é sua trilha musical que mais se assemelha a outras produções do período.

\section{Sinopse de Os Fuzis}

O filme, lançado comercialmente em janeiro de 1965, se passa no nordeste brasileiro dos anos 1960. É sabido que "o Nordeste sempre teve uma forte presença na cultura brasileira em todos os ramos da arte, e no cinema não poderia ser diferente" (DÍDIMO, 2010, p. 29). Essa temática foi recorrente no início da década entre produtores audiovisuais, especialmente os ligados ao Cinema Novo. Os Fuzis (1963), Vidas Secas (1963) e Deus e o Diabo Na Terra Do Sol (1964) são considerados como a "trilogia do sertão", representando "um Brasil ensolarado de onde emerge os conflitos sócio-políticos" (NAHUD, 2013, p. 1).

A "fuga das cidades" em direção ao campo nos cenários dos filmes na década de 1960 se consolidou rapidamente. Eikmeier (2010) comenta que, de 1962 a 1964, as principais produções já estavam todas em circulação. Pensar isso no período é intrigante, pois, mesmo com as limitações da comunicação, diversas pessoas trilharam caminhos convergentes e muito disso se deve à articulação política dos realizadores.

[...] pressionados pelos movimentos sociais e pelo contato ímpar com a dificuldade da luta no campo, estudantes começam a se interessar em retratar o assunto. Eduardo Coutinho dá início em 62 às filmagens de Cabra marcado pra morrer e estabelece um estreito contato com as ligas camponesas de Pernambuco [...]. O Cinema Novo de Ruy Guerra com Os Fuzis, de Glauber Rocha com Barravento e Deus e o Diabo na Terra do Sol, ou Nelson Pereira dos Santos com Mandacaru Vermelho e Vidas Secas, 
A trilha musical de Moacir Santos para Os Fuzis no contexto das produções... Lucas Zangirolami Bonetti

consolida esta atitude cinematográfica de escapar dos limites do estúdio e da cidade, bem como do formato melodramático e procura compreender o país na complexidade dos assuntos que se tinha por intenção avaliar (EIKMEIER, 2010, p. 66-67).

No caso de Os Fuzis a história mostra um grupo de soldados que chega até uma cidade na qual toda a população se encontra no limiar da fome, pois os únicos alimentos que restam se encontram em um armazém e a função dos soldados é proibir o acesso do povo à comida para vendê-la em outro lugar. Ocorre um empecilho quando o caminhão que deveria levar a comida embora quebra e todos precisam esperar a peça chegar, enquanto a comida estocada se deteriora. O motorista do caminhão é Gaúcho (Átila lório), ele já pertenceu à tropa, mas se desligou por não concordar com suas atribuições e sua postura, que era "sistematicamente atirar sobre camponeses esfomeados para proteger o bem dos ricos" (BERNARDET, 2007, p. 92-93). A população da cidade cultiva um certo misticismo pela figura de um boi, que supostamente traria chuva, e "as práticas místicas em torno do boi respondem às práticas não menos místicas em torno dos fuzis" (BERNARDET, 2007, p. 92-93). Ao final, percebe-se que a elevação do boi a uma figura de santo, ou algo do gênero, não se sustenta diante das necessidades básicas: o boi é morto e homens, mulheres e crianças formam uma multidão ávida, se debatendo por uma fatia de carne.

Schwarz (1966) levanta a hipótese de o filme, na verdade, ter propostas estéticas paralelas, uma mais documental e outra ficcional, sendo essa reflexão um fio condutor da estética cinemanovista:

O filme de Rui Guerra, que é uma obra prima, não procura "compreender" a miséria. Pelo contrário, ele a filma como a uma aberração, e dessa distância tira a sua força. À primeira vista é como se de cena em cena alternassem duas fitas incompatíveis: um documentário da seca e da pobreza, e um filme de enredo (SCHWARZ, 1966, p. 218). 
A trilha musical de Moacir Santos para Os Fuzis no contexto das produções... Lucas Zangirolami Bonetti

Sobre os homens fardados do filme e a significação social retratada por eles, Schwarz comenta também que eles "mandam, mas são mandados; se olham para baixo são autoridades, se olham para cima são povo também. Resulta [em] um sistema de contradições, que será baliza para o enredo" (1966, p. 218).

A situação retratada por Ruy Guerra ganha esse caráter documental, pois é sabido que tais contradições no abuso de poder eram parte do cenário do cotidiano nordestino. Dídimo, pesquisador do cangaço no cinema brasileiro, constata que "o poder das armas era utilizado para manter a ordem, e grupos de homens armados eram formados com essa finalidade, a mando de cada coronel" (DÍDIMO, 2010, p. 19).

Os filmes de cangaço no cinema brasileiro são comuns desde a década de 1920, contudo foi nos anos 1960 que a temática se expandiu e ganhou mais adeptos. Mas nem todos os filmes que se passam no Nordeste e representam narrativas sociais que se enquadram nesse gênero fílmico. Os Fuzis não faz parte do gênero cangaço em si, apenas apresentando a mesma ambientação. Dídimo (2010, p. 34) também explica o fato em sua tese de doutorado:

Nesse sentido, podemos relacionar Os Fuzis [...] e Vidas Secas [...] como sendo filmes ligados à tradição da cultura popular nordestina que poderiam ter abordado o cangaço como tema principal, mas que trabalharam a questão da seca, do latifúndio, das injustiças sociais, do coronelismo, em outro nível. O cenário é o mesmo, a caatinga do sertão nordestino, mas os personagens são outros.

Posto isso, vemos que a estrutura narrativa da obra audiovisual dialoga diretamente com todo um contexto político e social vivido no Nordeste brasileiro e que foi veementemente retratado nas telas dos cinemas por vários cineastas contemporaneamente à sua produção. Vale comentar também que a narrativa de $O s$ Fuzis se conecta diretamente com a icônica Guerra de Canudos, que ocorreu no sertão da Bahia na última década do século XIX. A 
A trilha musical de Moacir Santos para Os Fuzis no contexto das produções... Lucas Zangirolami Bonetti

ligação mais explicita se dá por volta dos 20 minutos do filme, na fala de um velho senhor, que cita o ocorrido em Canudos como se um confronto semelhante estivesse prestes a ocorrer na cidade ${ }^{7}$.

\section{Trilha musical de Os Fuzis}

Como já mencionado, das produções em que Moacir Santos trabalhou o filme mais afinado com os preceitos e ideias motrizes do Cinema Novo é, sem dúvida, Os Fuzis. Contudo, não é tão comum em filmes do período se encontrar maestros compositores responsáveis pelas trilhas musicais. Essa tradição era ligada à década anterior, quando os estúdios tinham uma verba maior para cada produção. Naturalmente, isso acabou influenciando o plano musical dos filmes dos dois períodos.

É perceptível que existe uma forte ligação religiosa em boa parte da trilha musical, como no caso das Cantorias diegéticas ${ }^{8}$, que ajudam a configurar a representação social do filme. "O ambiente de miséria e profunda religiosidade que caracteriza ainda hoje o interior brasileiro sertanejo será posteriormente retomado por Moacir Santos na composição da trilha sonora para o filme Os Fuzis" (DIAS, 2014, p. 28). Dias também faz um paralelo entre as conturbadas relações familiares retratadas no cinema de cangaço e a própria trajetória de Moacir.

Poucas inserções musicais são ouvidas ao longo do filme e isso resulta em muitos momentos de silêncio, quando são ouvidos apenas os ruídos diegéticos e os esparsos diálogos. Essa característica acaba se tornando uma marca estética importante, podendo ser comparada à trilha musical de Vidas Secas ${ }^{9}$.

Foi possível encontrar em um caderno de apontamentos de Moacir Santos, resgatado por Dias em sua pesquisa de campo, uma

7 Para mais informações sobre a relação da Guerra de Canudos com o cinema brasileiro, em diferentes períodos, ver o trabalho de Santos (2012).

8 Claudia Gorbman "adota os termos diegético e não-diegético [ou extra-diegético] para identificar os dois tipos de inserção da música na trilha, quais sejam, a música cuja fonte pode ser identificada na ação filmada (source music) e aquele cuja fonte não pode ser identificada, respectivamente" (CARRASCO, 1993, p. 60).

9 Para mais informações sobre a música de Vidas Secas, veja o capítulo 2.4 de Guerrini (2009) intitulado Não há música em Vidas Secas? 
A trilha musical de Moacir Santos para Os Fuzis no contexto das produções... Lucas Zangirolami Bonetti

espécie de roteiro para a trilha musical de Os Fuzis, com anotações separadas por rolo do filme. Nota-se que todo o uso de música diegética foi pensado pelo compositor, que também foi o diretor musical da produção. Segue uma reprodução do manuscrito:

Figura 1 - "Roteiro" da trilha musical de Os Fuzis. Caderno Pré-Coisas, c. 1960. Acervo MS (DIAS, 2014)

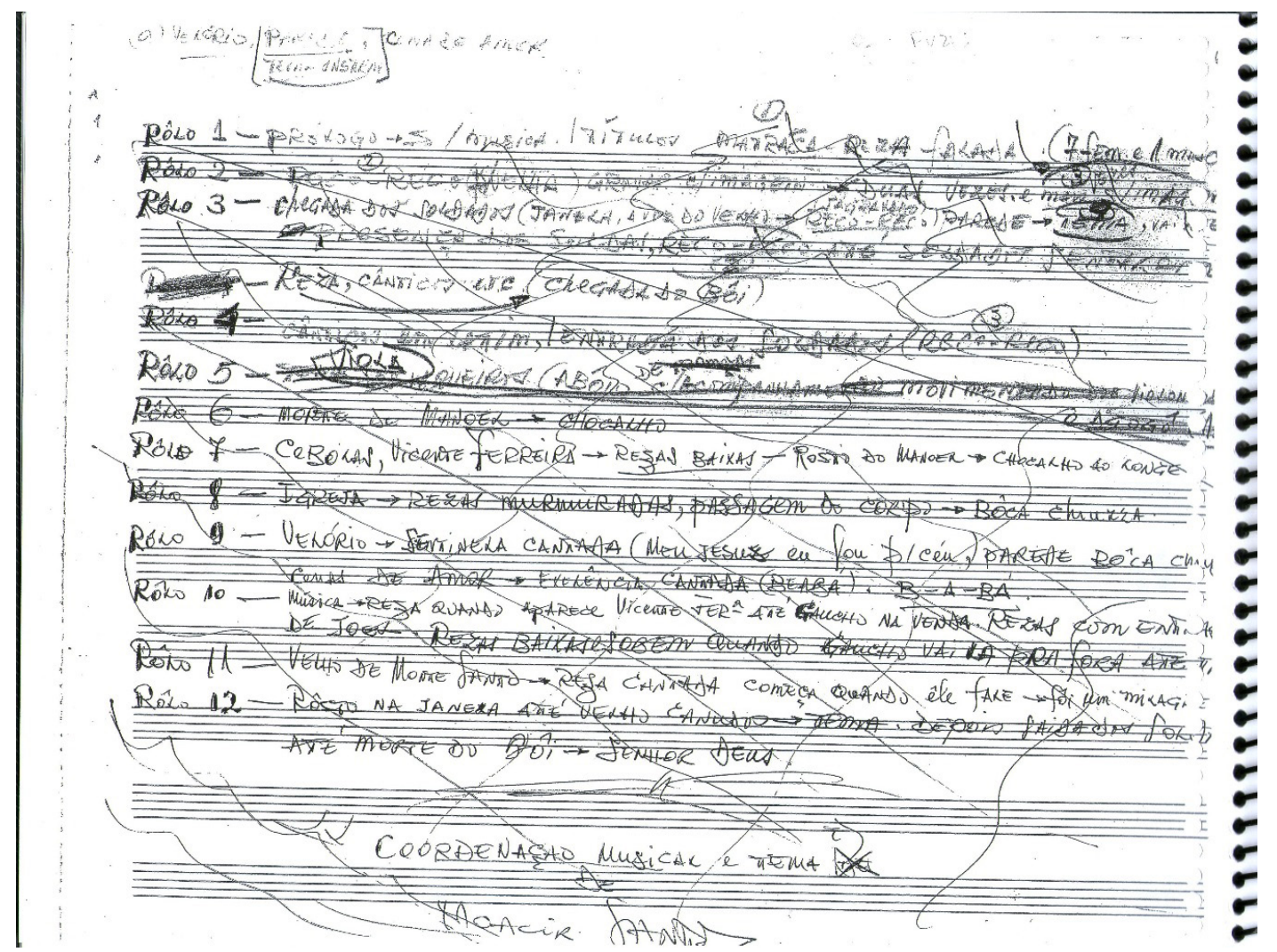

\section{Tema principal}

O tema principal da trilha musical de Os Fuzis apresenta características que levaram Moacir a compor a música "Bluishmen", que seria lançada em 1972 no disco The Maestro. Ele tem uma função muito importante na articulação dramático-narrativa do filme, abrindo e fechando ciclos de acontecimentos, e é escutado apenas três vezes ao longo das quase duas horas de duração do 
A trilha musical de Moacir Santos para Os Fuzis no contexto das produções... Lucas Zangirolami Bonetti

longa-metragem. Além disso, é a única música extra-diegética de todo o filme, o que ressalta ainda mais sua representatividade.

Nas três aparições do tema principal no filme ele é executado apenas por um violoncelo solo com uma interpretação bastante solta e livre. O ritmo da melodia alterna a rítmica ternária de semínimas com a binária de colcheias, passando por notas longas, que ora servem de repouso e ora impulsionam o desenvolvimento do perfil melódico. A composição se baseia em duas seções, uma sugerindo o modo de Dó lídio (com uma passagem cromática marcante entre mi e dó), e outra que sugere um modo de Sib que não fica bem definido (só são executadas fundamental, segunda maior, sétima maior, quinta justa e sexta maior, nessa ordem, podendo ser parte da escala maior ou da escala menor melódica, por exemplo).

A primeira aparição ocorre durante os Créditos Iniciais, aos 5 minutos e 41 segundos, e é aí que ele se estabelece como tema principal, pois adquire uma carga dramática muito forte logo no início do filme.

Ex. 1 - Primeira aparição do tema principal, dentro da trilha musical de Os Fuzis (5m 41s)
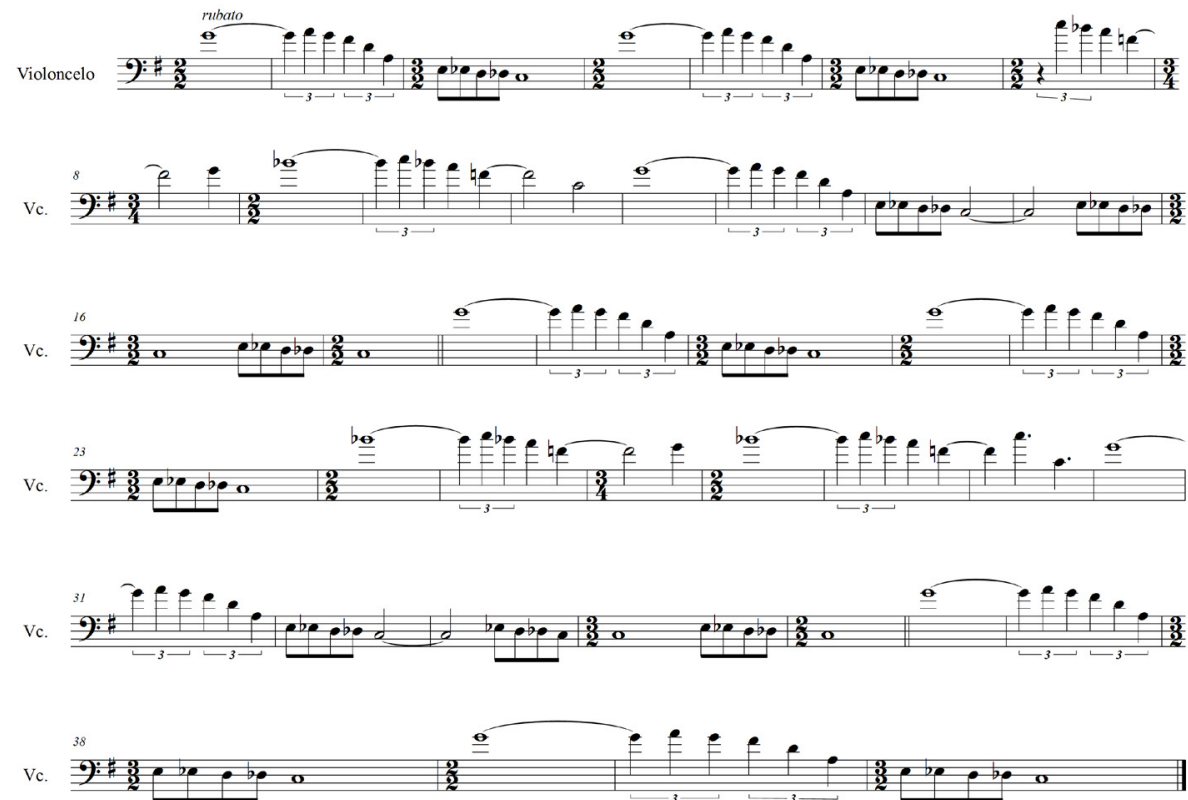
A trilha musical de Moacir Santos para Os Fuzis no contexto das produções... Lucas Zangirolami Bonetti

A segunda aparição do tema é inserida em outro momento crucial da história em si; logo depois da chegada dos soldados, que na verdade é representada na tela como a "chegada dos fuzis", pois as armas são efetivamente o centro das atenções. Um velho senhor da cidade começa a falar diretamente com o espectador, olhando-o nos olhos, e diz:

\begin{abstract}
“Era mil e duzentos soldados, tudo bem armado. Foi uma luta terrível, mataram quinze mil almas que só pediam pra viver em paz nesse sertão. Tirante as mulheres e crianças que fugiram pelo campaio, ficou tudo aqui enterrado no chão. Quem tinha bom santo não abandonou Canudo, não senhor. Eu mesmo, em pessoa, não tive a graça de conhecer meu bom Jesus. Mas vi gente falou como eu tô falando com o senhor. Sei que ele andava a um palmo da terra, todos disseram, seus pés não tocavam no chão".
\end{abstract}

Antes de o senhor terminar seu discurso, a segunda aparição do tema é ouvida, aos 20 minutos e 30 segundos, pontuando assim a chegada dos soldados à cidadela e insinuando a mudança na estrutura social que isso representa, com desfechos possivelmente trágicos, como os de outrora.

\title{
Ex. 2 - Segunda aparição do tema principal, dentro da trilha musical de Os Fuzis (20m 30s)
}

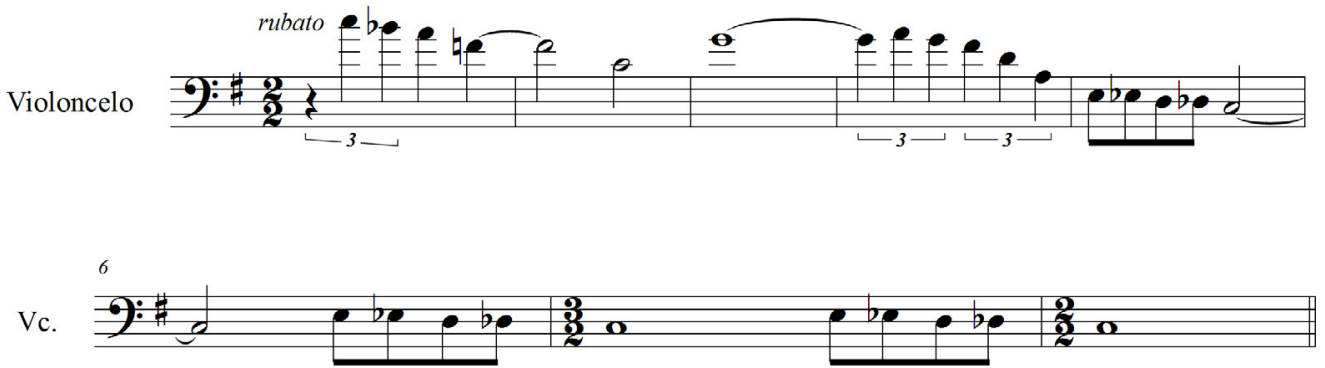


A trilha musical de Moacir Santos para Os Fuzis no contexto das produções... Lucas Zangirolami Bonetti

A terceira aparição, ouvida em 1 hora, 46 minutos e 52 segundos, fecha o ciclo: os soldados estão de saída da cidade e com o "dever cumprido", como um deles diz. Mário, o soldado que se afeiçoou a Luiza, reflete abraçado com seu fuzil e nos mostra, com sua expressão facial, que na verdade a missão fora um fracasso e era hora de bater em retirada.

Ex. 3 - Terceira aparição do tema principal, dentro da trilha musical de Os Fuzis (1h 46m 52s)
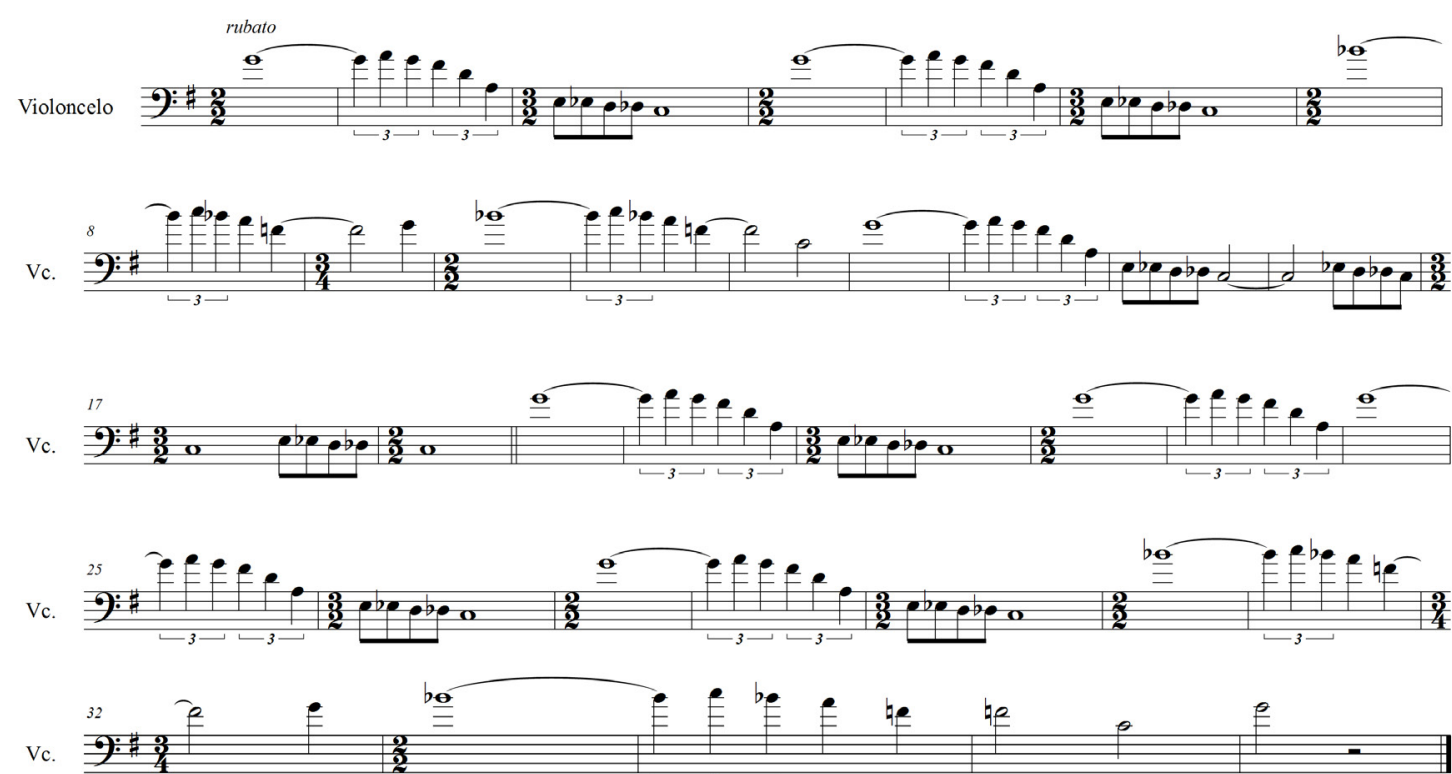

\title{
De tema principal à introdução de "Bluishmen"
}

\begin{abstract}
Bluishmen são os negros que, de tão retintos, chegam a ser azulados. Esses são de uma tribo africana que fica na costa, na mesma direção do Ceará. Deve ter sido o mesmo lugar, na época em que os continentes eram uma coisa só. A paisagem é a mesma, praias, coqueiros, palmeiras... (SANTOS. In: Encarte do disco Ouro negro, 2001, p. 24)
\end{abstract}


A trilha musical de Moacir Santos para Os Fuzis no contexto das produções... Lucas Zangirolami Bonetti

O tema principal é a única inserção musical do filme que veio a ser gravada posteriormente. Tal tema foi recomposto na introdução da faixa "Bluishmen", presente no disco The Maestro, de 1972. Esse tema aparece pouquíssimas vezes ao longo da trilha musical de Os Fuzis, diferentemente de outras trilhas musicais de Santos, mais densas.

A composição para o filme é executada apenas por um violoncelo solo e aparece três vezes, cada uma com um recorte diferente da mesma melodia. Pelo fato de ser composta para apenas um instrumento, a interpretação do tema é muito livre e sem grandes compromissos com métrica e andamento. Já na introdução de "Bluishmen" o mesmo tema se transforma e adquire uma nova sonoridade. A instrumentação utilizada é muito maior: trompa, trompete, naipe de sopros, piano, contrabaixo e percussão. Com esse drástico aumento na densidade da instrumentação, novas linhas são somadas à melodia já conhecida: um ostinato polirrítmico ao piano se torna o fio condutor da composição; um contrabaixo acrescenta mais força e direcionamento ao andamento; um grande naipe de sopros cria contraste com motivos rítmicos paralelos e não necessariamente sincronizados ao início das frases da melodia principal; e uma percussão simples e pontual realça todas as cores instrumentais com uma execução que valoriza a sonoridade metálica dos pratos. A melodia, antes ouvida no violoncelo, agora é tocada por uma trompa, depois dobrada por um trompete, ambas meio tom acima da originalmente composta. É provável que essa mudança tenha se dado para uma melhor execução nos instrumentos de sopros. Por fim, as fórmulas de compasso apresentam diferenças significativas quando comparadas as duas versões. 
A trilha musical de Moacir Santos para Os Fuzis no contexto das produções... Lucas Zangirolami Bonetti

Ex. 4 - Trecho inicial da introdução de "Bluishmen", presente no disco The Maestro

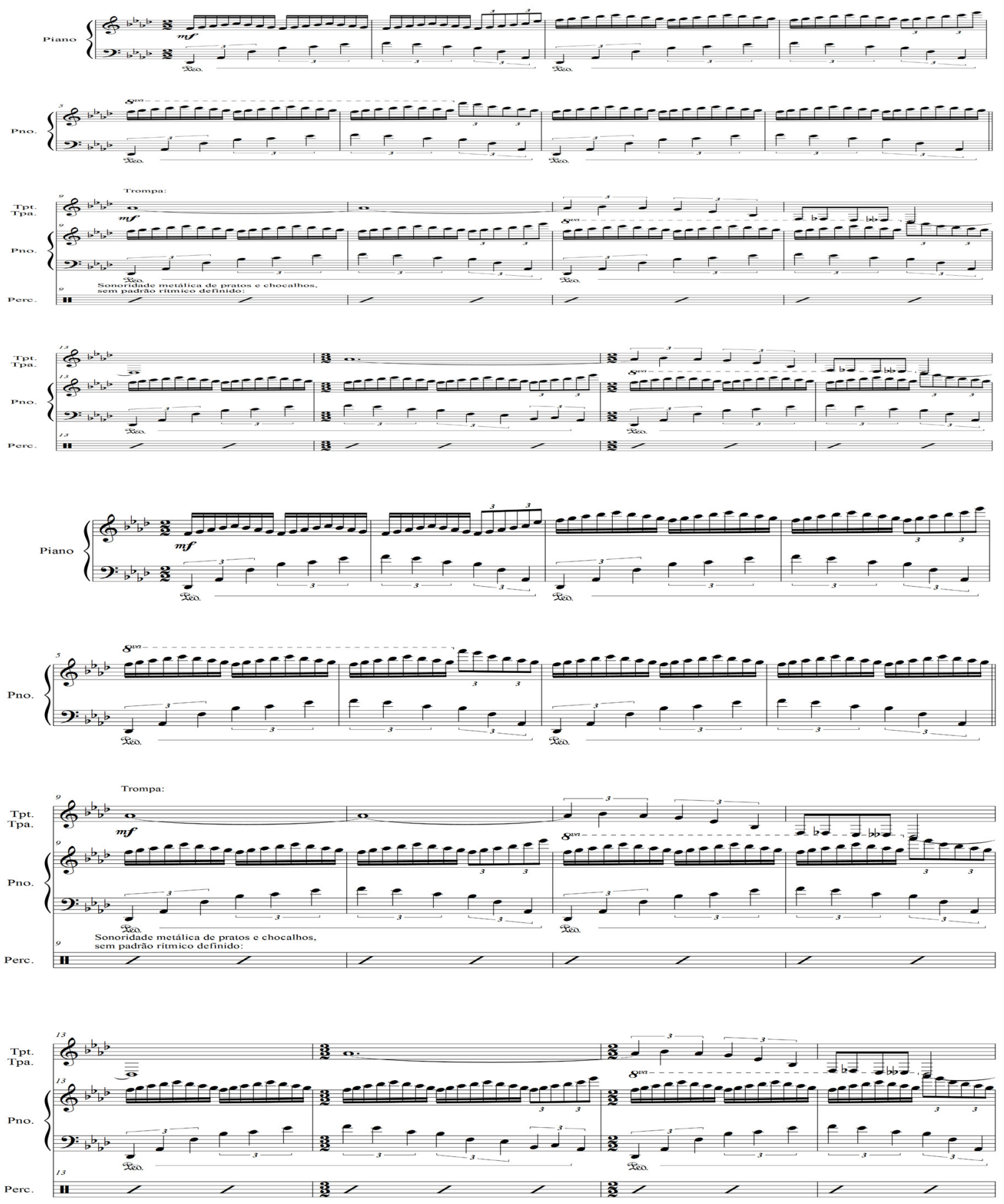


A trilha musical de Moacir Santos para Os Fuzis no contexto das produções... Lucas Zangirolami Bonetti

\section{Percussão diegética e falsa-diegética ${ }^{10}$}

Ouvimos essa percussão três vezes ao longo da trilha musical e, logo na primeira vez, aos 15 minutos e 50 segundos, podemos ver a fonte sonora na tela. O som é de uma espécie de reco-reco feito por uma mola em uma pequena caixa de metal, raspado por um pedaço de metal que aparenta ser uma chave de fenda. No início, vemos uma senhora com a mola na mão, falando de como ficou cega e tocando esporadicamente.

Na segunda inserção, em 17 minutos e 23 segundos, a senhora começa a executar um ritmo regular, que passa rapidamente a ser ouvido de forma extra-diegética na sequência seguinte. Essa estrutura percussiva é tocada exatamente quando os soldados estão chegando à cidade e, de certa forma, sua música representa a marcha ritmada desses homens.

\footnotetext{
De fato, no debate sobre trilha sonora, o período que envolve os anos 1960 e 1970 rompe com as fronteiras entre o ruído e a música, com ruídos que passam a ocupar o lugar da música, como [...] o entrelaçamento entre a música de Moacir Santos e os sons das marchas dos soldados na entrada da cidade de Os Fuzis (CARVALHO, 2009 apud FREIRE, 2009, p. 43-44).
}

Já na terceira aparição, totalmente extra-diegética (ou falsa-diegética), o ritmo faz alusão novamente à "marcha" dos soldados. Durante a sequência vemos vários deles caminhando até a mercearia com seus fuzis em punho, onde eles esbanjam autoridade em uma demonstração de poder, intelectual e bélico: uma espécie de aula sobre o armamento é lecionada ao povo que se aglomera no espaço, com descrições milimétricas de funcionamento, manejo e poder de fogo de suas armas. De início, a mulher apenas pontua notas curtas e isoladas em seu instrumento, mas a partir da segunda aparição o ritmo transcrito abaixo passa a dominar

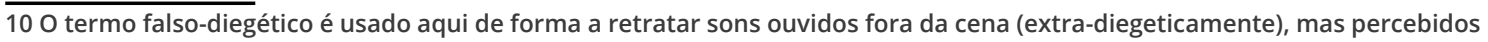
pelo espectador como diegéticos. 
A trilha musical de Moacir Santos para Os Fuzis no contexto das produções... Lucas Zangirolami Bonetti

a estrutura musical executada. As semicolcheias pontuadas do primeiro tempo dão uma impressão de fanfarra marcial ao trecho.

Ex. 5 - Percussão diegética e falsa-diegética, dentro da trilha musical de Os Fuzis $(15 \mathrm{~m} 50 \mathrm{~s}, 17 \mathrm{~m} 23 \mathrm{~s}$ e $32 \mathrm{~m} 33 \mathrm{~s})$

Reco-reco (mola)

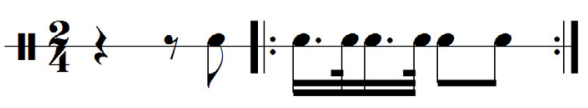

A figura da mulher cega tocando seu instrumento improvisado remete aos músicos/cantadores/repentistas do Nordeste, sendo muito comum os filmes da época retratarem músicos com alguma deficiência tocando nas ruas por alguns trocados. Outra questão importante é a ambiguidade da diegese nas diferentes inserções. A primeira aparição do som é acompanhada da imagem de sua fonte sonora, fixando assim essa relação no inconsciente espectador. Posteriormente, quando o som é ouvido sem a imagem, a associação é direta, pois é de fácil reconhecimento por meio da memória.

\section{Cantorias diegéticas (benditos, sentinelas e canções nordestinas)}

São encontradas diversas inserções musicais que correspondem às Cantorias diegéticas ao longo do filme. Em geral, elas apresentam uma forte carga religiosa e são justificadas tanto pelo desenrolar da história quanto pela representação social. Chamaremos aqui tais inserções de Cantorias, tomando como referência estudos de Ramalho (2002), nos quais a pesquisadora se debruçou sobre a música de tradição oral nordestina. A definição de Cantoria proposta por ela está mais calcada no fazer musical do repente e dos famosos duelos de improvisação vocal, contudo 
A trilha musical de Moacir Santos para Os Fuzis no contexto das produções... Lucas Zangirolami Bonetti

é perceptível que diversas semelhanças podem ser encontradas com as Cantorias presentes em Os Fuzis. A opção pelo termo em questão serve também para referenciar as inserções musicais a toda carga social e geográfica que a própria etimologia da palavra carrega e, assim, localizar a tradição pertinente ao Nordeste brasileiro em suas manifestações sociais e religiosas. A seguir todas as Cantorias serão devidamente descritas e analisadas a partir do contexto fílmico.

A primeira Cantoria ocorre aos 26 minutos e 56 segundos e apresenta um forte caráter religioso. Vê-se na tela uma procissão do povo junto do boi santificado. Por onde o animal passa são colocadas folhas de palmeiras, como se fosse um tapete, para que ele não entre em contato com o chão, ato que por si só já mostra o tratamento diferenciado que o boi recebe, tal qual um rei com seu tapete vermelho. A maior parte da letra é incompreensível, mas é possível ouvir algumas vezes a palavra "misericórdia", fazendo alusão a uma espécie de culto para que a chuva caia e melhores tempos cheguem. Musicalmente, o trecho é composto em um modo menor e apresenta o padrão pergunta-resposta, sendo a "pergunta" de um grupo vocal pequeno e a "resposta" de um coro maior.

A segunda Cantoria é ouvida em 1 hora, 6 minutos e 52 segundos e também acontece sob um pano de fundo religioso. Nessa sequência um grupo de pessoas faz uma procissão em homenagem ao homem que acabara de morrer, vítima dos soldados que estavam atirando irresponsavelmente em um cabrito e, ao errar, alvejaram um morador da cidade. O canto é totalmente melismático, ou seja, não apresenta nenhuma letra e é construído no modo de Ré frígio.

A terceira Cantoria apresentada na trilha musical é ouvida em 1 hora, 12 minutos e 35 segundos e é o desenvolvimento da sequência anterior. Agora, o povo da cidade se encontra dentro de uma das casas, no velório do morto, e a melodia cantada em uníssono é modal maior, valorizando a $6^{\mathrm{a}}$ maior e excluindo a $7^{\mathrm{a}}$. Ao final dessa mesma sequência, ouvimos novamente um pequeno trecho da segunda Cantoria. 
A trilha musical de Moacir Santos para Os Fuzis no contexto das produções... Lucas Zangirolami Bonetti

Em uma hora, 17 minutos e 8 segundos, ouvimos de início a Cantoria dois novamente, mas dessa vez extra-diegeticamente, pois Mário, um dos soldados, e Luiza se encontram em um beco afastado. Repentinamente, a trilha musical muda para a quarta Cantoria, que alterna frases de coro e voz solo feminina. Na sequência em questão, Luiza titubeia diversas vezes e o soldado força para agarrá-la. No exato momento em que a música cessa, ela se rende e cai em seus braços de vez.

A quinta Cantoria é ouvida em dois momentos: a primeira em uma hora, vinte e quatro minutos e cinquenta e sete segundos e ocorre enquanto o caminhão é carregado com a comida que está prestes a ir embora. Toda a população se encontra posicionada em torno do veículo cantando, como um lamento. Notadamente, os soldados ficam intimidados, como podemos ver na conversa de dois deles: "Soldado 1: Não estou gostando da cara dessa gente. Soldado 2: Vê lá rapaz, não vá sujar as calças." Já o segundo momento que ouvimos a quinta Cantoria é em 1 hora, 29 minutos e 22 segundos. Na sequência um menino morre de fome e Gaúcho se revolta, dizendo para o pai do garoto: "Seu filho morreu de fome e você não fez nada, seu Covarde". Ele pega o fuzil de um dos soldados e atira contra o caminhão, iniciando uma confusão generalizada. Durante os dois trechos a cantoria se dá apenas pelas mulheres em cena, e esse coro feminino entoa uma melodia lenta em modo maior.

A sexta Cantoria pode ser ouvida em 1 hora, 42 minutos e 26 segundos, sua utilização pode ser considerada como falsa-diegética, devido ao fato de que não é possível ver as pessoas cantando dentro do enquadramento da câmera. Contudo, a inserção serve para localizar o ambiente, pois perto do local poderia ter algum grupo cantando, fora de quadro. O caráter religioso permanece aqui também: junto da Cantoria vemos e ouvimos um senhor contar sobre um suposto santo milagreiro que passara por aquelas terras em outro tempo, fazendo alusão, de certa forma, a Antônio Conselheiro. A Cantoria é executada apenas por um coro feminino, as vozes apresentam um timbre bastante "áspero" e gutural. 
A trilha musical de Moacir Santos para Os Fuzis no contexto das produções... Lucas Zangirolami Bonetti

Em 1 hora, 49 minutos e 55 segundos a primeira Cantoria é ouvida novamente. Dessa vez todos cantam em volta do boi sagrado, pedindo misericórdia por suas vidas, quando um homem se aproxima do animal e desfere repentinamente um corte na garganta do bicho. Todos se assustam e param de cantar: o boi sagrado está morto.

A única cantoria que de fato se diferencia de todas as outras descritas anteriormente é a que ocorre aos 45 minutos e 11 segundos. Ela é composta por uma voz masculina solo, acompanhada de um violão, sendo que o violão basicamente dobra a melodia em terças. A letra da Cantoria é nitidamente uma oração a São José, sendo que, no plano imagético, vê-se a figura de São José sendo carregada em uma procissão. Segue a letra transcrita:

"José, aqui, tô no [sic] vossos pés.

Aqui, tô no [sic] vossos pés.

Dá-me paz em alma.

Deus e Jesus de Nazaré.

Quem quiser (a)judar [sic] na fé,

se apegue em São José,

se apegue em São José.

É um santo milagroso,

Deus e Jesus de Nazaré.

Os pés da Virgem sagrada

Um perfeito oferer [sic]

Um de..."

Pela letra, pudemos averiguar que se trata de um "[...] bendito de chuva: [que] são cantos populares da tradição oral, cantados em novenas, terços e procissões. Em geral são iniciados com as palavras "Bendito" e "Louvado seja" (LIMA, 2013, p. 73). Um bendito tradicionalmente cantado a São José foi encontrado no trabalho 
A trilha musical de Moacir Santos para Os Fuzis no contexto das produções...

Lucas Zangirolami Bonetti

de Lima, mostrando que a Cantoria de Os Fuzis é basicamente uma variação dele:

Meu divino São José,

Aqui estou em vossos pés,

Pedindo água com bondança

E meu Jesus de Nazaré.

Quem quiser chuva na Terra

Se apegue com São José,

Que é um Santo milagroso,

Que é da vossa santa fé (2013, p. 74).

Musicalmente, a melodia se desenvolve no modo de Dó lócrio e não apresenta seções formais muito bem estruturadas, com números de compasso irregulares.

Segue a transcrição da melodia do trecho:

Ex. 6 - Bendito do violeiro, dentro da trilha musical de Os Fuzis (45m 11s)

Voz

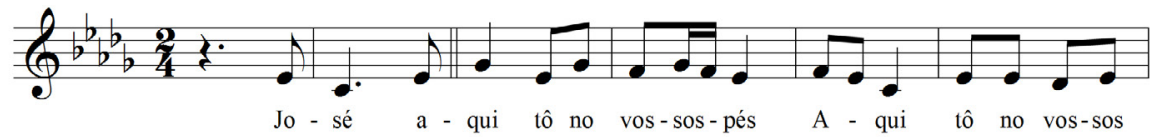

Voz

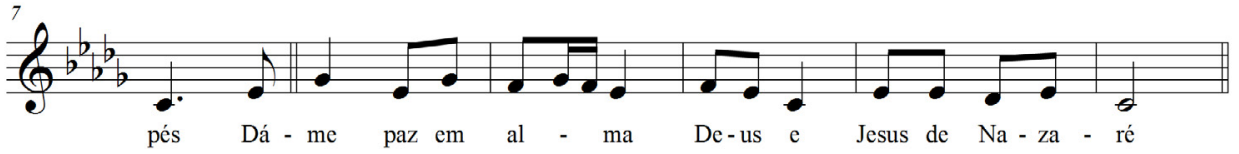

Voz

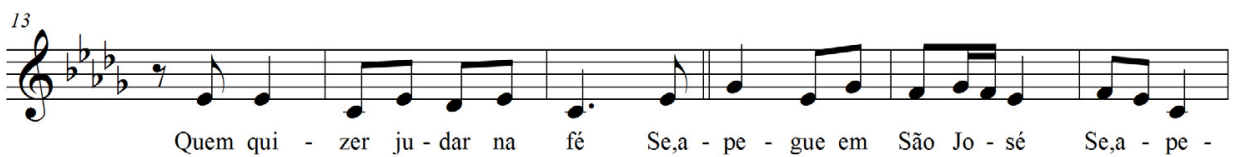

Voz
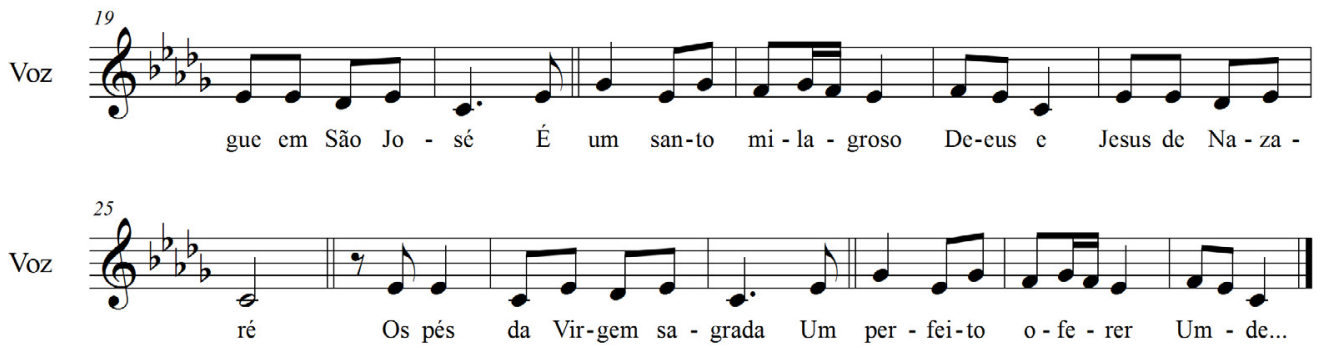
A trilha musical de Moacir Santos para Os Fuzis no contexto das produções... Lucas Zangirolami Bonetti

\section{Créditos Iniciais}

A sequência dos Créditos Iniciais apresenta uma construção poética muito particular, que soma diversos planos sonoros presentes em todo o filme. Pode-se perceber a sobreposição de três diferentes camadas: o primeiro plano é constituído pela aparição inicial do tema principal da trilha musical, tocado por um violoncelo solo; o segundo é o de uma Cantoria religiosa da reza "Ave-Maria", tal qual as cantorias vistas anteriormente, contudo mais difundida e não regional como as outras; e o terceiro plano é formado por intervenções de percussão com o mesmo timbre do reco-reco de mola tocado pela senhora durante o filme, aqui, essa percussão não apresenta um padrão rítmico regular, sendo ouvido mais como um ruído.

É possível se fazer um paralelo da trilha musical do trecho (e até mesmo de todo o filme) com o conceito de trilha sonora, como se houvesse uma espécie de simulacro das três camadas da banda sonora: música, diálogos e ruídos, sendo o tema principal o representante da música; as Cantorias uma representação musical da faixa dos diálogos; e a percussão do reco-reco a representação dos ruídos.

\section{Silêncio narrativo}

Por fim, outro aspecto muito marcante da trilha musical de Os Fuzis, é o fato de boa parte do tempo não haver música alguma concomitantemente com as imagens. Como visto, esse tipo de característica não é incomum no cinema brasileiro dos anos 1960, entretanto o emprego nesse caso apresenta algumas particularidades.

Desde o advento do cinema sonoro, muitas mudanças técnicas e estéticas aconteceram ao longo das décadas. Especialmente se considerarmos as realidades sociais de cada produção. No Brasil, é possível notar que no período em que grandes companhias 
A trilha musical de Moacir Santos para Os Fuzis no contexto das produções... Lucas Zangirolami Bonetti

como a Atlântida e a Vera Cruz dominavam o mercado, a trilha musical era carregada na quantidade e na densidade. Já a partir dos anos 1960, quando a lógica de produção audiovisual sofreu uma grande reviravolta, o uso abundante de inserções musicais foi caindo, mostrando um amadurecimento poético dos autores, aliado às condições financeiras vigentes. Essa mudança não foi um fenômeno exclusivo do Brasil, em um nível global a música foi se tornando cada vez mais escassa ao longo das décadas. "Havendo menos música, seu impacto tornou-se, ao mesmo tempo, muito maior, ampliando a capacidade de expressão audiovisual. A música caminhou no sentido da redução e não do acúmulo" (CARRASCO, 2003, p. 170).

Visto isso, consideramos que o silêncio na trilha musical do filme em questão tem um sentido poético, de forma a agregar valor à narrativa. Pois, "devido à força expressiva que alcança, é possível indagá-lo enquanto ruptura sonora, se ponderada à mudança de atenção que a 'ausência de sons' resulta na audiência ao deslocar sua atenção" (TEREZANI, 2012, p. 3). Para o silêncio ser efetivamente percebido pelo espectador é necessário que ele seja bem articulado com o som ou o som musical na fase de montagem e mixagem, de modo a "recriar sua sensação de vazio através de outros sons, uma vez que, absoluto, o silêncio viria de encontro ao princípio clássico de cinema dominante e sua busca pela ilusão e identificação (TEREZANI, 2012, p. 6-7).

Podemos perceber tal aspecto em Os Fuzis: o silêncio é intercalado com poucas inserções musicais, mas elas ganham um frescor especial a cada aparição, sem contar a valorização do material musical, que passa a ser de mais fácil assimilação, enfatizando a função narrativa da trilha musical.

\section{Considerações finais}

Os Fuzis foi produzido em um período inicial de experimentação sonora no cinema brasileiro e o uso do silêncio foi um passo 
A trilha musical de Moacir Santos para Os Fuzis no contexto das produções... Lucas Zangirolami Bonetti

importante para a consolidação de uma nova estética. Os filmes dos anos 1960 e 1970 "descrevem assim a importância de experimentar novas formas de inserir o som, bem como de entender o silêncio como elemento constitutivo das trilhas sonoras" (COSTA, 2006, p. 204).

Dentre as possíveis utilizações do silêncio nas trilhas musicais/ sonoras, Claudia Gorbman (1987) categoriza três tipos: silêncio musical diegético, silêncio não-diegético e silêncio estrutural. Em Os Fuzis, a maior presença é a do silêncio musical diegético e, dadas as circunstâncias, ele acaba se tornando tão "incômodo" quanto o silêncio não-diegético, pois a história se passa no interior do Nordeste, com muitos planos em locações desérticas, onde não existem muitos sons diegéticos audíveis. O pouquíssimo uso de música nessa trilha musical pode ser comparado a uma poética afirmação de Tarkovski: "Pode acontecer que, para dar maior autenticidade à imagem cinematográfica e levá-la a sua máxima intensidade, seja preciso abandonar a música" (1998, p. 191). Uma trilha musical carregada de inserções em nada auxiliaria na construção narrativa do filme, dada a metáfora com a fome dos personagens, que (sobre)vivem em uma cidade onde falta tudo para uma vida digna.

Por fim, os créditos iniciais do filme indicam que a "coordenação musical e tema" foram dirigidos por Moacir Santos, citando explicitamente os termos: "benditos, sentinelas e canções nordestinas". A partir dessa informação, retirada dos letreiros do próprio filme, e também de anotações pessoais em seu caderno de apontamentos (reproduzido anteriormente), podemos afirmar que Santos teve papel decisivo na escolha de todas as etapas da trilha musical e não só da composição do tema principal, como se poderia pensar em um primeiro momento. Essa é a trilha musical com menos inserções e menor densidade na faixa sonora de toda a carreira de Santos, mesmo assim pôde-se perceber que ela apresenta um alto nível de refinamento na estruturação da articulação dramático-narrativa da música. 
A trilha musical de Moacir Santos para Os Fuzis no contexto das produções... Lucas Zangirolami Bonetti

\title{
Referências
}

\author{
Bernardet, Jean-Claude. Brasil em Tempo de Cinema: ensalo sobre \\ o CINEMA BRASILIIRO de 1958 a 1966. São Paulo: Companhia das Letras, \\ 2007.
}

BONetti, lucas Zangirolami; CARrasco, Claudiney Rodrigues. A trilha SONORA NAS PRODUÇÕES CINEMATOGRÁFICAS BRASILEIRAS DOS ANOS 1960: O eXemplo de Glauber Rocha. In: ANPPOM 2012, João Pessoa. 2012. v. 22. P. 332-339.

BONETTI, Lucas Zangirolami. A trilha musical como gênese do processo criativo na obra de Moacir Santos. Dissertação de mestrado. Campinas: UNICAMP, 2014.

BONETtI, Lucas Zangirolami. Moacir Santos ghostwriter: a composição de trillas musicals no período Norte-Americano. Tese de doutorado. CamplNAS: UNICAMP, 2018.

Bruce, Graham. Alma Brasileeira: Music in the films of Glauber Rocha. In: JOHNSON, R. e STAM, R. (orgS) Brazilian Cinema. Londres e Toronto: Associeted University Press, 1982. Capítulo 31, p. 290-305.

Carrasco, Ney. Trilha Musical: Música e articulação fílmica. Dissertação de Mestrado. São Paulo: ECA/USP, 1993.

CARRASCO, Ney. Sygkhronos: a formação da poética musical do Cinema. São Paulo: Via Lettera, 2003.

costa, Fernando de Moaes. O Som no Cinema Brasileiro. Tese de Doutorado. Rio de Raneiro: UFF. 2006.

DIAS, Andrea Ernest. Moacir Santos, ou os caminhos de um músico brasileiro. Rio de Janeiro: Folma Seca, 2014.

dídimo, Marcelo. O Cangaço no Cinema Brasileiro. São Paulo: AnnabLUME, 2010.

Diegues, Carlos. Cinema Brasileiro: ideias e imagens. Segunda Edição. Porto Alegre: Ed. Universidade/UFRGS/MEC/SESU/PROED, 1999. 
A trilha musical de Moacir Santos para Os Fuzis no contexto das produções... Lucas Zangirolami Bonetti

ElKMElER, Martin. A música de Remo Usai no cinema brasileiro. Tese de Doutorado. BahiA: UNICAMP, 2010.

FINK, Camila; CALHADO, Cyntia. Uma Perspectiva histórica do Cinema BRASILEIRO: O CINEMA COMO INSTRUMENTO DE CRÍTICA SOCIAL E POLÍTICA. 2008. DISPONIVEL EM: HTTP://WWW.CINECALEIDOSCOPIO.COM.BR/UMA_PERSPECTIVA_HISTORICA_DO_CINEMA_BRASILEIRO_PARTE3.HTML. ACESSO EM: 03/07/2018.

Freire, Rafael de Luna (Org.). Nas trilhas do cinema brasileiro. 1 ed. Rio de Janeiro: Tela Brasilis, 2009.

GORBMAN, Claudia. Unheard melodies - NarRative film music. Londres: LONDON, BFL, 1987.

GUERRINI JR., IRINEU. A MÚSICA No CINEMA BRASILEIRO: OS INOVADORES ANOS sessenta. São Paulo: Terceira Margem, 2009.

jOhnSon, Randal; StaM, Robert. Brazilian Cinema. Nova lorque: CoLUMBIA UNIVERSITY PRESS, 1995.

LiMA, Ednalva Alves. Crenças ambientais de camponeses maranhenses relacionadas ao uso e conservação da Água. Dissertação de Mestrado. BRASÍLIA/DF: UNB, 2013.

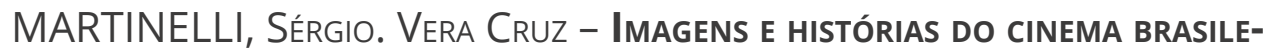
IRO. SÃo PAULO: @BOOKS, 2002.

NAHUd, Antonio. A trilogia do sertão. O Falcão Maltês. Maio de 2013. IN: HTTP://OFALCAOMALTES.COM/CINEMA-NOVO/A-TRILOGIA-DO-SERTAO. ACESSO EM: 25 JUL. 2013.

OS FuZIS. Direção: Ruy Guerra. Produção: Jarbas Barbosa. Roteiro: Ruy Guerra, Pierre Pelegri. Música: Moacir Santos. Intérpretes: Nelson Xavier, Paulo César Peréio, Hugo Carvana e outros. 80 min. Brasil, 1965.

Ramalho, Elba Braga. Cantoria Nordestina: pensando uma estética da cultura oral. IASPM, Latin-American Branch. Cidad de Mexico, 2002.

SAntos, F. Os Sertões do Cinema Brasileiro: a Guerra de Canudos no Cinema Novo e no cinema após a Retomada. BOCC. Biblioteca Online de CIÊNCIAS dA COMUniCAÇÃO, v. 1, P. 1-8, 2012. 
A trilha musical de Moacir Santos para Os Fuzis no contexto das produções... Lucas Zangirolami Bonetti

SANTOS, Moacir. In: Encarte do disco Ouro negro. São Paulo: MP,B, 2001. 2 CDs.

SCHWARZ, Roberto. 0 cinema e Os Fuzis. Revista Civilização Brasileira, v. 1, N. 9/10, P. 217-222, SET.-NOV., 1966.

TARKOVSKI, AndReI ArsenseVICH. Esculpir o tempo [tRAdução: JefFerson Luiz Camargo]. 2 ed. São Paulo: Martins Fontes, 1998.

tereZANi, João Henrique Tellaroli. O Vazıo da Trilha: Considerações SOBRE O SILÊNCIO E SUA ATUAÇÃO NA NARRATIVA CINEMATOGRÁFICA. CUAC, COLOquio Universitario de Análisis Cinematrográfico. Cidad de México, 2012. 